\title{
Parazitoit Yaşının Trichogramma pintoi Voegele (Hymenoptera: Trichogrammatidae) Performansı Üzerine Etkisi
}

\author{
Nihal Özder ${ }^{*}$ Esra Tayat \\ Tekirdağ Namık Kemal Üniversitesi, Ziraat Fakültesi, Bitki Koruma Bölümü, 59100 Süleymanpaşa, Tekirdağ \\ *Sorumlu yazar: nozder@nku.edu.tr
}

Geliş Tarihi: 18.06.2018

Kabul Tarihi: 22.11.2018

$\ddot{O} z$

Çalışmada Trichogramma pintoi Voegele erginlerinin farklı yaşlarda Ephestia kuehniella Zeller (Lepidoptera: Pyralidae) yumurtaları ile karşılaşmasının parazitoit performansı üzerine etkisi araştırılmıştır. Çalışmalar $25^{\circ} \mathrm{C} \pm 1^{\circ} \mathrm{C}$ 'de \% 65-70 nem ve $16 / 8$ saat aydınlık/ karanlık koşullarında yürütülmüştür. Çalışma sonucunda parazitlenen yumurta sayısında ergin yaşının etkili olduğu, yaşlı bireylerin parazitledikleri yumurta sayılarında düşmelerin olduğu belirlenmiştir. Ergin ömrünün birinci gününde yumurta ile karşılaşan parazitoitlerin ortalama 159,80 adet yumurta bıraktıkları, ergin olduktan 7 gün sonra yumurta ile karşılaşan parazitoitlerin ise ortalama 27,30 adet yumurta parazitlenebildikleri belirlenmiştir. Parazitoitlerin canlı kalma oranları ise $\% 46,70$ oranına düşmüştür. Çalışma sonucunda parazitoit performansı açısından ergin parazitoitin yaşının önemli olduğu salımlar ve kitle üretimi sırasında dikkat edilmesi gerektiği kanısına varılmıştır.

Anahtar Kelimeler: Trichogramma pintoi, Dişi yaşı, Ömür, Doğurganlık, Canlı kalma oranı

\section{Effects of the Parasitoid Age on the Performance of Trichogramma pintoi Voegele (Hymenoptera: Trichogrammatidae)}

\section{Abstract}

In this study, effect of ages on parasitoid performance of Trichogramma pintoi Voegele (Hymenoptera: Trichogrammatidae) on Ephestia kuehniella Zeller (Lepidoptera: Pyralidae) eggs were investigated. The studies has been conducted within a $25^{\circ} \mathrm{C} \pm 1^{\circ} \mathrm{C}$ temperature, \%65-70 relative humidity and 16 hours light 8 hours dark periods per day. At the end of research survival and ratio of adult parasitoids were affected by the parasitoids ages. As a result of the study, it was also determined that young females parasitized more hosts than older females. It was determined that parasitoids exposed to eggs on the first day of the adult's life had an average of 159.80 eggs left and that parasitoids encountered with eggs after 7 days of being mature could parasitized an average of 27.30 eggs. The survival rate of parasitoids decreased to $46.70 \%$.

Keywords: Trichogramma pintoi, Female age, Longevity, Fecundity, Survival rate

\section{Giriş}

Trichogramma türleri yumurta parazitoiti olmaları ve pek çok zararlı Lepidoptera türüne etkili bir şekilde kullanılabilmeleri nedeni ile büyük önem taşımaktadırlar. Pek çok ülkede yaygın olarak kullanılmaktadırlar (Li, 1994). Trichogramma türlerinin kitle üretimleri, biyolojik mücadele programlarında salımlar sırasında pek çok parazitoite ihtiyaç duyulması nedeni ile büyük önem taşımaktadır. Bu nedenle ülkemizde ve yurt dışında konukçu yumurta tercihleri, üretim sıcaklıkları, depolama koşulları üzerinde pek çok çalışma yürütülmüştür (Özpınar, 1994; Uzun,1994; Garcia ve Tavares, 1995; Masetti ve ark., 2010; Özder ve Kara, 2010; Kara ve Özder, 2017; Özder ve Tayat, 2018).

Yine Trichogramma türlerinin kitle üretiminde besin çeşidi çok büyük önem taşımaktadır. Yapılan çalışmalar sonucunda besinin çeşidinin parazitoitin ömrü, parazitleme gücü, parazitlenmiş yumurtaların açılma oranı, meydana gelen bireylerde erkek/dişi oranları üzerinde etkili olduğu belirtilmektedir ( Bigler ve ark., 1987; Saljoqi ve Kattak, 2007; Shearer ve Atanassov, 2004; WittingBissinger ve ark., 2008; Diaz ve ark., 2012; Zhu ve ark., 2013; Özder ve Demirtaş, 2017).

Trichogramma türleri doğaya salındıklarında yaşam sürelerinde çok kısa sürede içersinde konukçu yumurtasını bulmalılar. Biyolojik mücadele programları açısından parazitoit yaşının parazitoit performansına etkisi önemli olmasına rağmen bu konu fazla çalışılmamıştır. Farklı doğal düşmanların yaşının parazitoit performansı üzerine etkisi bazı araştırıcılarca irdelenmiştir (Rajapakse, 1992; Hentz, 1998; Honda ve Kainoh, 1998; Garcia ve ark., 2001). 
Agrotis segetum Denis\&Schiffermüller (Lepidoptera:Noctuidae), Heliothis armigera (Hübner)(Lepidoptera:Noctuidae), Ostrinia nubilalis (Hübner)(Lepidoptera:Pyralidae)gibi zararlılar üzerinde de etkili olan $T$. pintoi erginlerinin, farklı yaşlarda zararlı veya konukçu yumurtaları karşılaşmalarının parazitoit ömrü ve parazitledikleri yumurta sayısı üzerinde kitle üretimi veya doğa yapılan çalışmalar bulunmamaktadır. Yapılan bu çalışma ile bal ile beslenen erginlerin farklı yaşlardaki parazitoit performansları ortaya konmaya çalışılmıştır.

\section{Materyal ve Yöntem}

Ephestia kuehniella $25 \pm 1{ }^{\circ} \mathrm{C}$ sicaklık, \%60-70 oransal nem içeren karanlık koşulların sağlandığı iklim odasında buğday unu, kaba buğday kepeği ve mısır üzerinde yetiştirilmiştir (Özder, 2004). Yetiştirme odalarına alınan küvetler zaman zaman kontrol edilerek ergin çıkışları takip edilmiştir. Çıkan un güvesi erginleri her gün toplanarak yüzeyleri naylon tül ile kaplı yumurtlatma kaplarına geçirilmiştir. Yumurtlatma kapları plastik küvetlere yerleştirilerek karanlık odaya alınmış ve yumurtlatma kaplarındaki yumurtalar günlük olarak fırçalanarak toplanmıştır.

Trichogramma pintoi üretimi uygun bir konukçu olan E. kuehniella kullanılarak geliştirilmiştir. Stok parazitoit kültürlü $25^{\circ} \mathrm{C} \pm 1^{\circ} \mathrm{C}$ 'de $\% 65-70$ orantılı neme sahip laboratuvarda, 16 saat aydınlık 8 saat karanlık ortamda geliştirilmiştir. Yumurta kaplarından toplanan E. kuehniella yumurtaları üzerindeki yabancı maddelerden arındırılmıştır. Sonra şeritler halinde kesilmiş olan \% 10'luk arap zamkı sürülmüş beyaz kağıtlara yumurtalar serpilerek aktarılmış ve ergin parazitoitlerin beslenebilmeleri için kağıdın kenarlarına sulandırılmış bal damlaları sürülerek parazitoitlere verilmiştir. Denemeler 1,7x18 cm'lik cam tüplerde aynı yaşta yumurtalar ile yürütülmüştür.

Yeni ergin çıkışı yapan parazitoitler 100 er olacak şekilde 8 gruba ayrılmış ve sadece bal ile beslenmiştir. Daha sonra hemen, 1, 2, 3, 4, 5, 6 ve 7. günlerde farklı yaşlardaki dişi parazitoitlerin canlı kalma oranları hesaplanmıştır. Ele alınan 8 gruptaki farklı yaşlardaki dişi parazitoitlere günlük yumurta verilmiştir. Günlük gözlemler ile parazitoitlerin canlılıkları kontrol edilmiştir. Canlı kalan parazitoitlere her gün bal ve taze yumurta verilerek bir önceki gün verilen yumurtalar uzaklaştırılarak inkübatörde gelişmeleri için beklemeye alınmıştır. Parazitoitler ölünceye kadar yumurta vermeye devam edilmiş̧ir. Daha sonra parazitoitlerin yaşam süreleri ve parazitledikleri yumurta sayıları ile parazitlenen yumurtaların ergin ömrüne göre dağılımları kaydedilmiştir.

Tüm denemeler 10'ar tekerrürlü yürütülmüştür. Denemeler tesadüf parselleri deneme desenine göre kurulmuş, verilerin varyans analizleri sonucu Duncan testi ile değerlendirilmiştir.

\section{Bulgular ve Tartışma}

Araştırmada yaşamlarının farklı yaşlarda yumurta ile karşılaşan parazitoitlerin canlı kalma oranlarında farkların olduğu ve bu farklılığın istatistiki olarak önemli olduğu saptanmıştır $(p<0.00)$ $($ d.f. $=7)(\mathrm{F}=7500,536)$ (Çizelge 1). Parazitoitlerin canlı kalma oranları 7. günde yarı yarıya düşmüş ve $\% 46.70 \pm 0.48$ olarak belirlenmiştir. Farklı yaşlarda yumurta ile karşılaşan parazitoitlerin yaşama sürelerinin farklı olduğunu ve bu farklılıkların da önemli olduğu görülmektedir(p<0.00) (d.f. =7) $(\mathrm{F}=$ 27.068). Ergin hale geldikten bir gün sonra yumurta ile karşılaşmış bireylerde, yumurta ile karşılaştıktan sonraki yaşama süresi 9 gün olarak belirlenmişken, ergin hale geldikten sonra bal ile beslenmelerine rağmen ömürlerinin ancak 7 gününde yumurta ile karşılaşan bireylerde ise bu süre 5 gün olarak saptanmıştır (Çizelge 1). Ancak toplam yaşama sürelerine baktığımızda ise 6 . ve 7. yaş gibi geç yaşlarda yumurta ile karşılaşan parazitoitlerin canlı kalma süreleri düşse de, toplam yaşama sürelerinde bir artış olduğu belirlenmiştir.

Farklı yaşlarda konukçu yumurtası ile karşılaşmış parazitoitlerin parazitledikleri yumurta sayıları incelendiğine, 3 yaşında itibaren yumurta ile karşılaşmış parazitoitlerin parazitledikleri yumurta sayıları belirgin olarak düşüş göstermiştir $(\mathrm{p}<0.00)(\mathrm{F}=3684.890)$. Şekil 1' de görüldüğü gibi ömürlerinin 1. gününde yumurta ile karşılaşmış parazitoitlerin parazitledikleri yumurta sayıları kontroldeki parazitoitlere göre yarı yarıya azalmış, yedinci günde yumurta ile karşılaşmış parazitoitlerin parazitledikleri yumurta sayıları ise beşte birine düşmüştür. 
Çizelge 1. Farklı yaşlardaki Trichogramma pintoi erginlerinin canlı kalma oranları (\%), ömür (gün) ve parazitledikleri yumurta (adet) sayıları

\begin{tabular}{lllll}
\hline Parazitoit yaşı (gün) & $\begin{array}{l}\text { Canlı kalma } \\
\text { (\%) }\end{array}$ & oranı & Ömür (gün) & $\begin{array}{l}\text { Parazitlenen } \\
\text { yumurta } \\
\text { (adet) }\end{array}$ \\
\hline Kontrol & $100,00 \pm 0,00 \mathrm{a}$ & $14,20 \pm 1,03 \mathrm{a}$ & $159,80 \pm 3,57 \mathrm{a}$ \\
1 & $98,70 \pm 2,00 \mathrm{~b}$ & $10,00 \pm 1,33 \mathrm{de}$ & $76,80 \pm 2,84 \mathrm{~b}$ \\
2 & $94,60 \pm 0,69 \mathrm{c}$ & $10,20 \pm 1,03 \mathrm{de}$ & $67,20 \pm 3,53 \mathrm{c}$ \\
3 & $81,30 \pm 1,15 \mathrm{~d}$ & $9,50 \pm 0,70 \mathrm{e}$ & $45,60 \pm 2,64 \mathrm{~d}$ \\
4 & $76,50 \pm 0,97 \mathrm{e}$ & $10,30 \pm 0,67 \mathrm{de}$ & $43,10 \pm 2,48 \mathrm{~d}$ \\
5 & $70,70 \pm 0,67 \mathrm{f}$ & $10,60 \pm 0,69 \mathrm{~cd}$ & $33,40 \pm 3,06 \mathrm{e}$ \\
6 & $51,60 \pm 0,84 \mathrm{~g}$ & $11,30 \pm 0,67 \mathrm{bc}$ & $28,80 \pm 2,28 \mathrm{e}$ \\
7 & $46,70 \pm 0,48 \mathrm{~h}$ & $12,00 \pm 0,94 \mathrm{~b}$ & $27,30 \pm 1,81 \mathrm{e}$ \\
\hline
\end{tabular}

*Her bir sütunda aynı harf gösterilen ortalamalar arasındaki fark istatistiksel olarak önemsizdir ( $<<0.00)$.

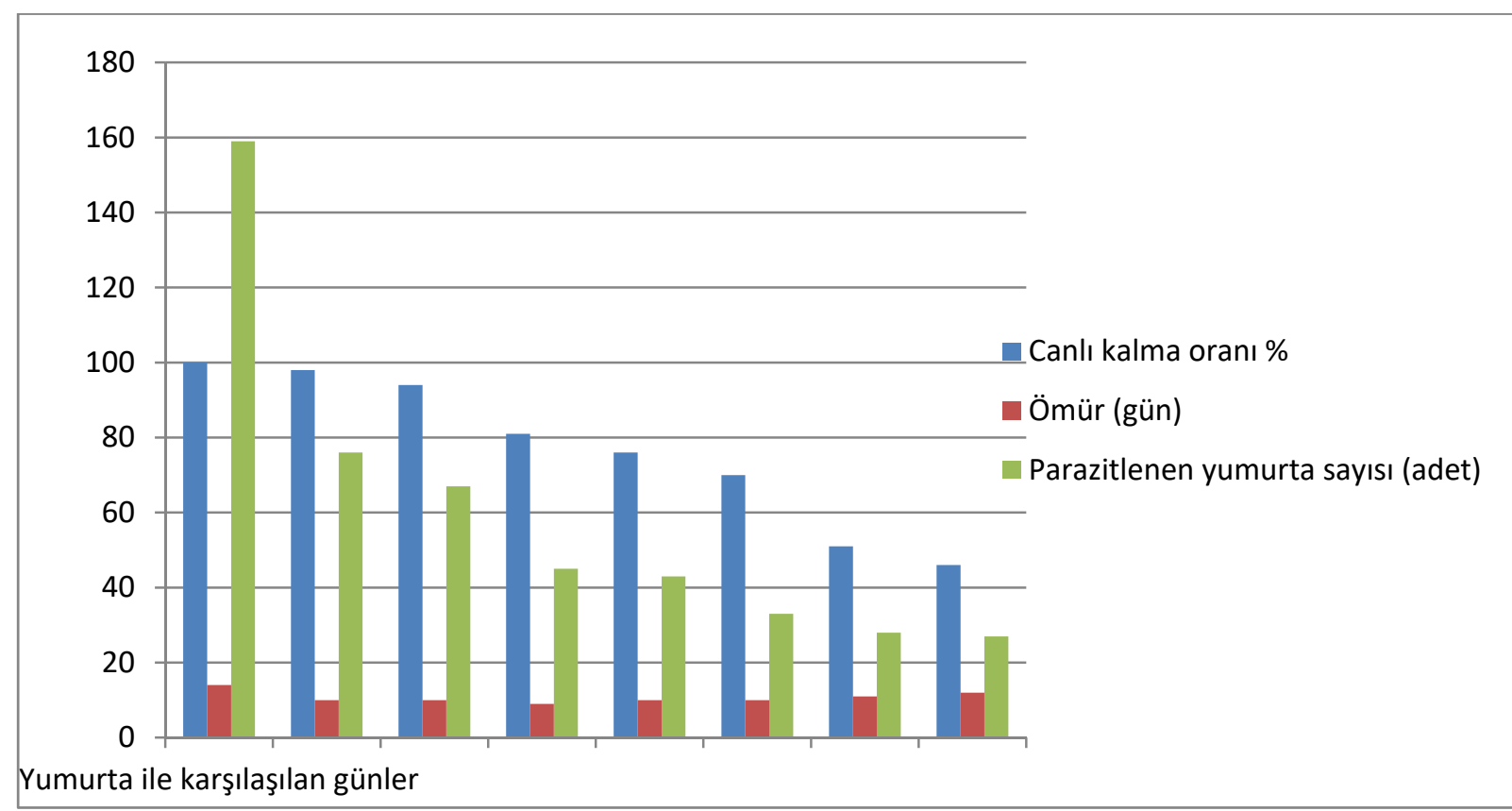

Şekil 1. Farklı yaşlardaki Trichogramma pintoi erginlerinin parazitoit performansları

Özder (2008), T. brassicae, T. cacoeciae ve T. evanescens erginlerini $5^{\circ} \mathrm{C}$ sıcaklıkta beş gün süre ile depolamıştır. Parazitoitlerin canlı kalma oranları ile parazitledikleri yumurta sayılarında düşmeler olduğu ancak $5^{\circ} \mathrm{C}$ sicaklığın uygun bulunduğu bildirmiştir. Trichogramma cordubensis ile yapılan çalışmalarda parazitoit yaşının ilerlemesi ile birlikte parazitlenen yumurta sayısında ve ergin bireylerin yaşama sürelerinde düşmelerin olduğu bildirilmiştir (Garcia ve ark., 2001). Ayvaz ve ark., (2008) yaptıkları çalışma sonucunda T. evanescens' in en yüksek parazitlediği yumurta sayısının 24 ile 90 saatlik bireylerde saptandığını bunun altındaki ve üstündeki yaşlarda parazitlenen yumurta sayısında düşmeler olduğunu bildirmiş̧lerdir. Ascogaster reticulatus Watanabe (Hymenoptera: Braconidae) dişilerinin genç yaşta parazitleme gücünün daha yüksek olduğu bildirilmiştir (Honda ve Kainoh, 1998). Farklı doğal düşmanlarla yapılan çalışmalarda da parazitoitlerin genç yaşta daha çok parazitleme gücüne sahip olduklarını bildirilmiştir (Amalin ve ark., 2005; Rajapakse, 1992; Hentz, 1998). Yapılan çalışmalar ile elde edilen sonuçların paralellik gösterdiği, genç parazitoitlerin daha başarılı olduğu belirlenmiştir. Parazitoitlerin ergin ömürleri süresince bıraktıkları yumurtalarının yaşam sürelerince günlere göre dağılımlarına baktığımızda ise, parazitoitlerin yaşamlarının sürelerinin ilk 5 gününde yumurtalarının \%85-90'nı bıraktıkları belirlenmiştir. Yine farklı yaşlarda yumurta ile karşılaşan bireyleri incelediğimizde en yüksek olarak ilk yumurta ile karşılaşılan gün en fazla yumurta bırakıldığ1 belirlenmiştir. Ancak parazitoit yaş1 ilerledikçe ilk yumurta karşılaşılan günler de 
parazitoitlerin parazitledikleri yumurta sayılarında azalma görülmüştür. Bir yaşındaki parazitoit ilk yumurta ile karşılaştığ gün 21 yumurta parazitlerken, 7 yaşındaki parazitoit yumurta ile karşıllaştı̆̆ ilk gün 11 yumurta parazitleyebilmiştir (Şekil 2, Şekil 3).

Çalışma sonucunda elde edilen verilerin daha önce yapılan çalışmalar ile paralellik gösterdiği belirlenmiştir. Her yaştaki parazitoitlerin yumurta ile karşılaştıkları ilk günde daha fazla yumurta parazitleyebildikleri kaydedilmiştir.

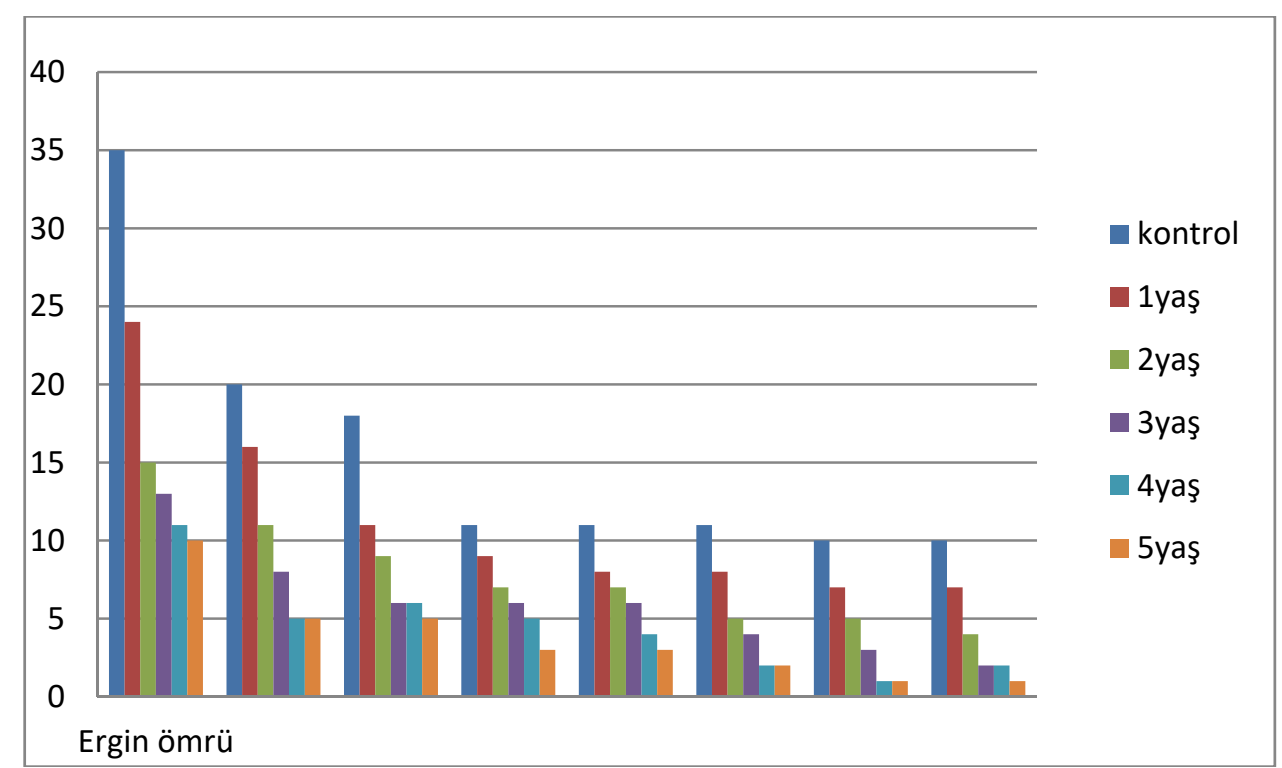

Şekil 2. Farklı yaşlardaki Trichogramma pintoi erginlerinin günlere göre bıraktıkları yumurta sayıları

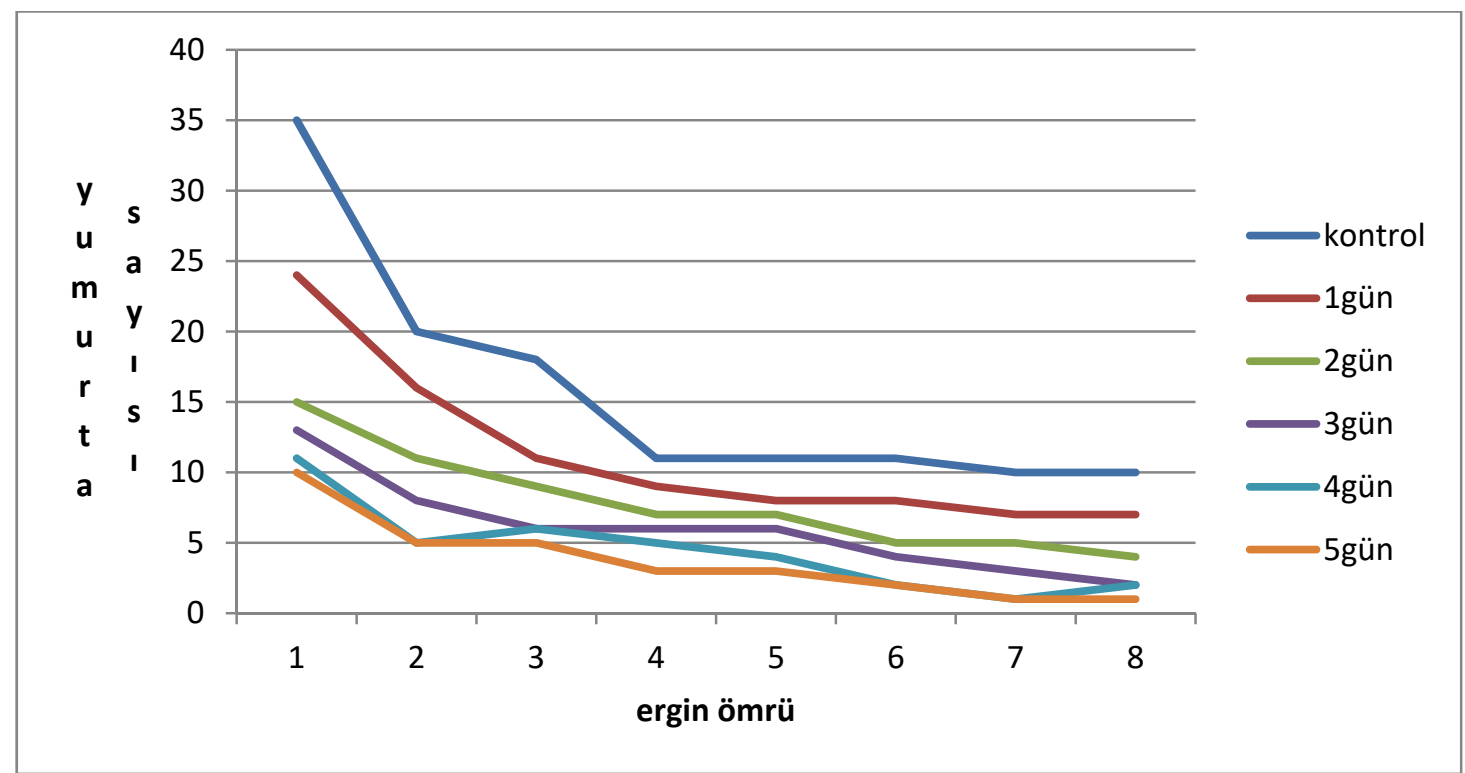

Şekil 3. Farklı yaşlardaki Trichogramma pintoi erginlerinin günlere göre bıraktıkları yumurta sayıları

Özder (2004), Farklı sıcaklıklarda depolanmış T. cacoeciae'nın ergin çıkışlarını takiben ilk günde en fazla yumurtayı koyduklarını depolama süresinin artması ile birlikte parazitoitlerin birinci günde parazitledikleri yumurta sayılarında da belirgin düşüş olduğunu belirtmiştir.

Özder ve Kara (2010), yaptıkları çalışmalarda ise E. kuehnielle ve $C$. cautella üzerinde farklı üç sıcaklıkta yetiştirdikleri $T$. brassicae, $T$. cacoeciae ve $T$. evanescens'in ergin ömürlerinin ilk üç gününde yumurtalarının büyük bir kısmını bıraktıklarını bildirmişlerdir. Araştırıcılar Trichogramma cordubensis 'in ilk yedi günde tüm yumurtalarının \%65 den fazlasını bıraktı̆̆ını kaydetmişlerdir (Garcia ve Tavares, 1995). Ayvaz ve ark. (2008), T. evanescens erginlerinin toplam yumurta üretiminin \%40-50'sini ilk dört günde bıraktıkları belirtilmiştir. Parazitoitlerin ergin ömürlerinin 

türlerinin yaşamlarının ilk gününde en fazla sayıda yumurtayı parazitledikleri çeşitli araştırıcılarca da ortaya koyulmuştur (Bigler ve ark., 1987; Steidle ve ark., 2001).

\section{Sonuç ve Öneriler}

Yapılan çalışma sonucunda T. pintoi için parazitoit yaşının önemli olduğu belirlenmiştir. Dişi parazitoitlerin bal ile beslenmelerine rağmen, ömürlerinde büyük değişiklikler olmamakla birlikte canlı kalma oranları ve parazitledikleri yumurta sayıları bir hayli düşmüştür. Yine ergin ömrünün farklı yaşlarında yumurta ile karşılaşan parazitoitlerin, ilk gün parazitledikleri yumurta sayılarında da büyük düşmeler görülmüştür. Kitle üretim çalışmaları ve doğa salımlarında bu konulara dikkat edilmesinin çalışmaların başarılı olmasında çok önemli olduğu kanısına varılmıştır. Kitle üretiminde yeni çıkmış parazitoitlerin kullanılmasının ve daha çok yumurta ile karşılaştırılmasının kitleriminde başarıyı arttıracağı belirlenmiştir. Özellikle doğada salımlar sırasında zararlı ile parazitoitin aynı zamanda olmasının mücadelenin başarısını etkileyeceği bu nedenle zamanlamaya dikkat edilmesi gerektiği ve salım zamanlarına ve zararlının biyolojisinin takibine dikkat edilmesi gerektiği sonucuna ulaşılmıştır.

\section{Kaynaklar}

Amalin, D.M., Pena, J.E., Duncan, R.E., 2005. Effects of host age, female parasitoid age, and host plant on parasitism of Ceratogramma etiennei (Hymenoptera: Trichogrammatidae). Florida Entomologist. 88, 7782.

Ayvaz, A., Karasu, E., Karabörklü, S., Tunçbilek, A.Ş., 2008. Effect of cold storage, rearing temperature, parasitoid age and irradiation on the performance of Trichogramma evanescens Westwood (Hymenoptera: Trichogrammatidae). Journal of Stored Products Research. 44, 232-240.

Bigler, F., Meyer, A., Bosshart, S., 1987. Quality assessment in Trichogramma maidis Pintureau et Voegele reared from eggs of the factitious hosts Ephestia kuehniella Zell. and Sitotroga cerealella (Olivier). Journal of Applied Entomology. 104, 340-353.

Diaz, M.F., Ramírez, A., Poveda, K., 2012. Efficiency of different egg parasitoids and increased floral diversity for the biological control of noctuid pests. Biological Control. 60 (2): 182-191.

Garcia P., Tavares J., 1995. Parasitic capacity, longevity and development of Trichogramma cordubensis (Hym., Trichogrammatidae) at three temperature regimes. Les Colloques de I'INRA. 73: 71-74.

Garcia, P.V., Wajnberg, E., Oliveira, M.L.M., Tavares, J., 2001. Is the parasitization capacity of Trichogramma cordubensis influenced by the age of the females? Entomologia Experimentalis et Applicata. 98, 219-224.

Hentz, M.G., 1998. Development, longevity, and fecundity of Chelonus sp.nr. curvimaculatus (Hymenoptera: Braconidae), an egg-larval parasitoidof pink bollworm (Lepidoptera: Gelechiidae). Environmental Entomology. 27, 443-449.

Honda, T., Kainoh, Y., 1998. Age-related fecundity and learning ability of the egglarvalparasitoid Ascogaster reticulatus Watanabe (Hymenoptera: Braconidae). Biological Control. 13, 177-18.

Kara, G., Özder, N., 2017. Trichogramma brassicae, Trichogramma cacoeciae ve Trichogramma evanescens' in konukçu ve yumurta yaşı tercihi üzerinde araştırmalar. Türkiye Bitki Koruma Bülteni. 57 (4): 423-432.

Lessard, E., Boivin, G., 2013. Effect of age and hunger on host-feeding behavior by female Trichogramma euproctidis (Hymenoptera: Trichogrammatidae). Canadian Entomologist. 145 (1): 53-60.

Li, Li-ying., 1994. Worldwide use of Trichogramma for biological control of different crops: A survey. In: Wajnberg, E. \& S. A. Hassan (eds.) Biological control with egg parasitoids. CAB International, Wallingford. 37-54 pp.

Masetti, A., Lanzoni, A., Burgio, G., 2010. Effects of flowering plants on parasitism of lettuce leaf miners (Diptera:Agromyzidae). Biological Control. 54 (3): 263-269.

Özder, N., Tayat, E., 2018. Storage possibilities of Trichogramma pintoi Voegele on eggs of Ephestia kuehniella Zeller. Tekirdağ Ziraat Fakültesi Dergisi. 15(1): 45-50.

Özder, N., 2004. Effect of Different cold storage periods on parasitization performance of Trichogramma cacoeciae (Hymenoptera, Trichogrammatidae) on Eggs of Ephestia kuehniella (Lepidoptera, Pyralidae). Biocontrol Science and Technology. 14 (5): 441-447.

Özder, N., 2008. Effect of cold storage of adult Trichogramma brassicae, T. cacoeciae and T. evanescens (Hym.: Trichogrammatidae). Archives of Phytopathology and Plant Protection. 41(4): 296-299.

Özder, N., Demirtaş, Ş., 2017. Effects of artificial diets and floral nectar on parasitization performance of Trichogramma brassicae Bezdenko, 1968 (Hymenoptera: Trichogrammatidae). Türkiye Entomoloji Dergisi. 41 (1):53-60. 
Özder, N., Kara, G., 2010. Comparative biology and life tables of Trichogramma cacoeciae, T. brassicae and T. evanescens (Hymenoptera: Trichogrammatidae) with Ephestia kuehniella and Cadra cautella (Lepidoptera, Pyralidae) as hosts at three constant temperatures. Biocontrol Science and Technology. 20 (3): 245-255.

Özpinar, A., 1994. Trichogramma evanescens Westwood (Hym., Trichogrammatidae)'in iki farklı konukçudaki yaşam çizelgesi. Türkiye Entomoloji Dergisi. 18 (2):83-88.

Rajapakse, R.H.S., 1992. Effect of host age, parasitoid age, and temperature on interspecific competition between Chelonus insularis Cresso, Cotesia marginiventris Cresson and Microplitis manilae Ashmead. Insect Science and Its Application. 13, 87-94.

Saljoqi, A.U.R., Khattak, A.S.K., 2007. Effect of different artificial diets on the efficiency and development of Trichogramma chilonis (Ishii) (Hymenoptera: Trichogrammatidae). Sarhad Journal of Agriculture. 23: $129-133$.

Schöller, M., Hassan, S.A., 2001. Comparative biology and life tables of Trichogramma evanescens and T. cacoeciae with Ephestia elutella as host at four constant temperatures. Entomologia Experimentalis et Applicata. 98, 35-40.

Shearer, P.W., Atanassov, A., 2004. Impact of peach extra floral nectar on key biological characteristics of Trichogramma minutum (Hymenoptera: Trichogrammatidae). Journal of Economic Entomology. 97: 789792.

Steidle, J.L.M., Rees, D., Wright, E.J., 2001. Assessment of Australian Trichogramma species (Hymenoptera: Trichogrammatidae) as control agents of stored product moths. Journal of Stored Products Research. 37, 263-275.

Uzun, S., 1994. Değişik sıcaklıklarda Trichogramma brassicae Bezdenko (Hymenoptera: Trichogrammatidae)'nin un güvesi (Ephestia kuehniella Zell.) yumurtalarında konukçu-parazit ilişkileri ve depolanması üzerinde araştırmalar. Türkiye III. Biyolojik Mücadele Kongresi Bildirileri, 25-28 Ocak 1994, Entomoloji Derneği Yayınları No:7, 431-440.

Witting-Bissinger, B.E., Orr, D.B.E., Linker, H.M., 2008. Effect of floral resources on fitness of the parasitoids Trichogramma exiguumm (Hymenoptera: Trichogrammatidae) and Cotesia congregata (Hymenoptera: Braconidae). Biological Control. 47 (2):180-186.

Zhu, P.Y., Gurr, G.M., Lu, Z.X., Heong, K.L., Chen, G.H., Zheng, X.S., Xu, H.X., Yang, Y.J., 2013. Laboratory screening supports the selection of sesame (Sesamum inducum) to enhance Anagrus spp. Parasitoids (Hymenoptera: Mymaridae) of rice planthoppers. Biological Control. 64 (1):83-89. 